Original Research Article

\title{
Rationality verses irrationality in fixed dose combinations: at a tertiary teaching hospital of rural Chhattisgarh, India
}

\author{
Ahmed Tabish*, Khan Tanveer A., Chandel N. B., Rao Anand, Mishra Chandresh
}

Department of Pharmacology, Government Medical College, Rajnandgaon, Chhattisgarh, India

Received: 12 February 2018

Revised: 21 April 2018

Accepted: 25 April 2018

*Correspondence to:

Dr. Ahmed Tabish,

Email: dr.tabishahmed@ gmail.com

Copyright: (C) the author(s), publisher and licensee Medip Academy. This is an openaccess article distributed under the terms of the Creative Commons Attribution NonCommercial License, which permits unrestricted noncommercial use, distribution, and reproduction in any medium, provided the original work is properly cited.

\begin{abstract}
Background: Rational drug prescribing can be defined as appropriate drugs prescribed in the right dose, at correct time intervals and for a sufficient duration. Irrational drug use is a common problem in many countries of the world.

Methods: A prospective observational study was conducted, total 300 patients attending various outpatient departments of tertiary health care rural hospital in Rajnandgaon district were interviewed and their prescriptions were analysed.

Results: Total 350 drugs were prescribed $60(17.14 \%)$ were prescribed by generic name and the rest $290(82.86 \%)$ were prescribed by brand name. Only 18 $(5.14 \%)$ drugs were not prescribed from hospital formulary. $264(75.43 \%)$ drugs were dispensed from hospital pharmacy. On the basis of rationality score $53 \%$ prescriptions were rational, $30 \%$ semi rational and 17\% irrational.

Conclusions: In a rural hospital, where hospital formulary is based on WHO Essential medicine list, hundred percent utilization of hospital pharmacy service doctors and patients would ensure rational prescribing benefits of the patients coming from rural and uneducated background.
\end{abstract}

Keywords: Chhattisgarh, FDCs, Prescribing, Rationality

\section{INTRODUCTION}

Fixed dose combinations (FDCs) are a combination product of two or more drugs in a single dosage form. Only some of the FDCs are rational and justified. The latest WHO essential medical list incorporates only 23 FDCs. To be combined two drugs should have approximately equal half-life, apparent volume of distribution and peak plasma concentration. Various advantages of fixed Drug combination (FDCs) are better efficacy, reduced adverse drug reactions, better compliance and reduced pill burden, delay development of drug resistance and broader spectrum of antibacterial activity. Various disadvantages of FDCs are emergence of resistance, increase in cost of therapy, difficulty in dose adjustmentand difficulty in adverse drug reaction (ADR) assessment. Presently, there is a lot of debate over rationality and irrationality of FDCs as a large number of FDCs are being manufactured every year with no therapeutic rationale. ${ }^{1}$ Irrational use of FDCs is a menace worldwide. The concept of rational FDCs is still in the embryonic phase in India. The market is flooded with large number of irrational FDCs.

Drug utilization studies aim to provide feedback to the prescriber and to create awareness among them about rational use of medicines. ${ }^{2}$ The assessment of drug utilization is important for clinical, economic and 
educational purposes. ${ }^{3}$ The study of prescribing patterns seeks to monitor, evaluate and if necessary, suggest modifications in the prescribing behavior of medical practitioners to make medical care rational and cost effective. ${ }^{4}$ So the aim was to evaluate the prescribing pattern of rational and irrational FDCs in a tertiary care teaching hospital of Rural Chhattisgarh.

\section{METHODS}

A prospective observational study was conducted for six months between June 2017 to December 2017 in a tertiary care teaching hospital of Rural Chhattisgarh, Government Medical College, Rajnandgaon. Study was conducted in the outpatient department (OPD) of medicine, surgery, obstetrics and Gynecology, ENT, ophthalmology, orthopaedics and skin. and their prescriptions were analysed. Total 300 prescriptions were assessed. FDCs prescribed were recorded and evaluated for their rationality. These FDCs were analyzed for rationality using WHO guidelines. The following guidelines were followed. According to WHO guidelines, FDCs are rational when they fulfill following criteria: ${ }^{5}$

- Active pharmacological ingredients (API) with complementary mechanism of action

- Decrease in the occurrence of resistance for antimicrobial agents

- Increase in the efficacy of combinations

- Decrease in the incidence of ADR or toxicity

- Increase in the compliance of drug therapy with decrease pill burden

- Decrease in the total cost of therapy

- Dose of each API should be appropriate for defining / larger group of population

The FDCs was termed as irrational if it shows:

- No justification for combination

- No increase in efficacy than individual drugs

The FDCs in this study were classified into four categories as rational, irrational, absurd and banned. ${ }^{6}$

Inclusion criteria were prescriptions from the medicine outpatient department. FDCs from the causality, wards, ICU, TB and Chest department as well as HIV unit were excluded.

\section{RESULTS}

Total 300 prescriptions were assessed. The chronic nature of the diseases and multi-modality approach being used makes the use of fixed dose combinations an inevitable option. The use of fixed dose combinations may help to bring down the cost and improve compliance. The percentage of FDCs prescribed in different departments has been shown in Figure 1. Maximum FDCs were prescribed in Medicine $(53.38 \%$ ), followed by Surgery $(21.52 \%)$, Obstetrics and Gynecology (11.98\%) then ENT
(8.45\%) Minimum FDCs were prescribed in the department of ophthalmology (4.67\%).

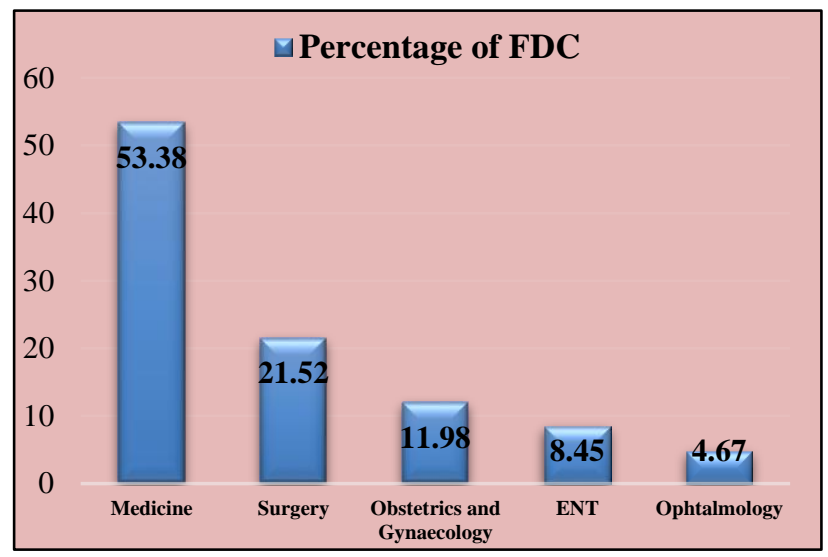

Figure 1: Percentage wise representation of various FDCs prescribed in different departments.

The first point is that each API of the combination should preferably be in the "essential medicines list (EML)" of the WHO or in the National List of Essential Medicines (NLEM) of India. The dose of each API should meet the requirements for a defined population group. The dose and the proportion of each API present in FDC should be appropriate for the intended use.

The combination should have the advantage of established evidence of efficacy and safety. The overall cost of the combination should preferably be less than the cost of the individual components. The FDC should facilitate either the reduction of the dose of individual drugs or their adverse effects. The pharmacokinetic (PK) parameters of each API should not be affected. There should be no unfavorable PK interaction between the APIs. In case of the PK parameters being different, the clinical benefits should be taken into consideration.

Finally, the individual drugs should have different mechanism of action. in Figure 2. On the basis of rationality score $53 \%$ prescriptions were rational, $30 \%$ semi rational and $17 \%$ irrational.

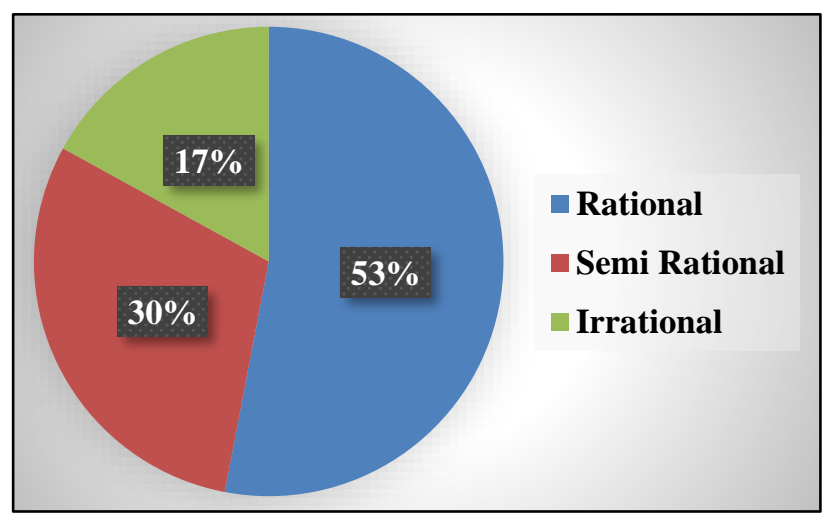

Figure 2: FDCs according to WHO guidelines depicting rationality status. 
The pharmacological classes of the FDCs prescribed with categorization as per WHO guidelines are shown in table 1. Hormonal preparations were the most rationally prescribed $(100 \%)$, followed by Multivitamins (92\%)and Hypolipidemic drugs $(78 \%)$.The least rationally prescribed class of drugs were anti-inflammatory (29\%).Whereas the most irrationally prescribed category was antidiabetic drugs (25\%). The most pressing concern with irrational FDCs is that they expose patients to unnecessary risk of ADRs.

Table 1: Classes of FDCs according to pharmacology mentioning categorization status.

\begin{tabular}{|lccll|}
\hline Class of FDC & No & Rational & $\begin{array}{l}\text { Semi } \\
\text { rational }\end{array}$ & Irrational \\
\hline $\begin{array}{l}\text { Antidiabetic } \\
\text { Drugs }\end{array}$ & 48 & $21(44 \%)$ & $15(31 \%)$ & $12(25 \%)$ \\
\hline $\begin{array}{l}\text { Anti- } \\
\text { hypertensive } \\
\text { Drugs }\end{array}$ & 59 & $37(63 \%)$ & $15(25 \%)$ & $07(12 \%)$ \\
\hline $\begin{array}{l}\text { Antimicrobial } \\
\text { Drugs }\end{array}$ & 77 & $31(40 \%)$ & $29(38 \%)$ & $17(22 \%)$ \\
\hline Antacids & 26 & $15(58 \%)$ & $10(38 \%)$ & $01(4 \%)$ \\
\hline $\begin{array}{l}\text { Anti- } \\
\text { inflammatory }\end{array}$ & 17 & $05(29 \%)$ & $9(53 \%)$ & $03(18 \%)$ \\
\hline $\begin{array}{l}\text { Anti- } \\
\text { histaminics }\end{array}$ & 13 & $10(77 \%)$ & $2(15 \%)$ & $01(8 \%)$ \\
\hline $\begin{array}{l}\text { Hypo- } \\
\text { lipidemics }\end{array}$ & 09 & $07(78 \%)$ & $1(11 \%)$ & $01(11 \%)$ \\
\hline $\begin{array}{l}\text { Multivitamins } \\
\text { Cold and } \\
\text { Cough Agents }\end{array}$ & 09 & $11(92 \%)$ & $06(0 \%)$ & $01(8 \%)$ \\
\hline $\begin{array}{l}\text { Hormonal } \\
\text { preparations }\end{array}$ & 06 & $06(100 \%)$ & 00 & 00 \\
\hline
\end{tabular}

Prescribing under a generic name is considered economical and rational but very few patients in the present study were prescribed generic drugs $(17.14 \%)$ as compared to proprietary drugs $(82.86 \%$ ) (Figure 3$)$. Poor prescribing of generic drugs can be because of concern about their quality. Our results were consistent with other studies done by Biswas et al, $(6.32 \%$ generic and $93.68 \%$ brand drugs) and Shankar et al, (32.6\% generic and $67.4 \%$ brand drugs). ${ }^{7,8}$

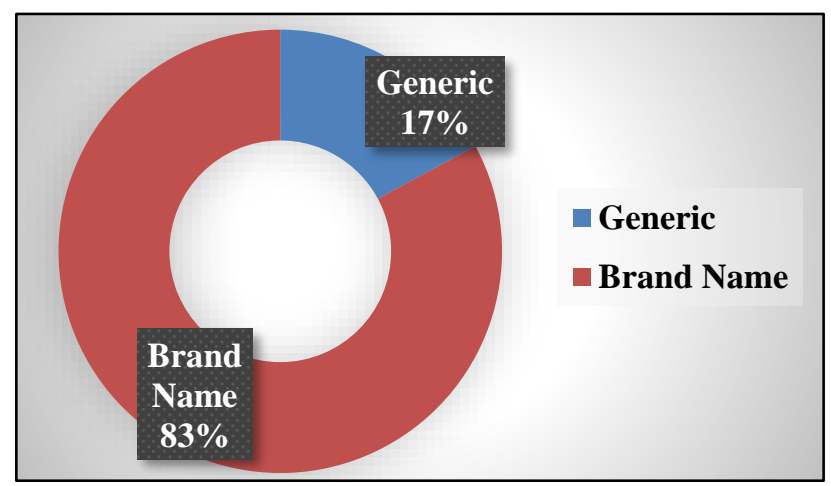

Figure 3: Prescription of drugs according to Nomenclature.
The utilization of hospital formulary was more as compared to drugs purchased from outside (Figure 4). 264 $(75.43 \%)$ drugs were dispensed from hospital formulary. As most of them were cheaper as those compared to their counterparts available in the market due to lower production cost of these preparations in the in-house pharmacy. Only 18 (5.14\%) drugs were purchased from outside..

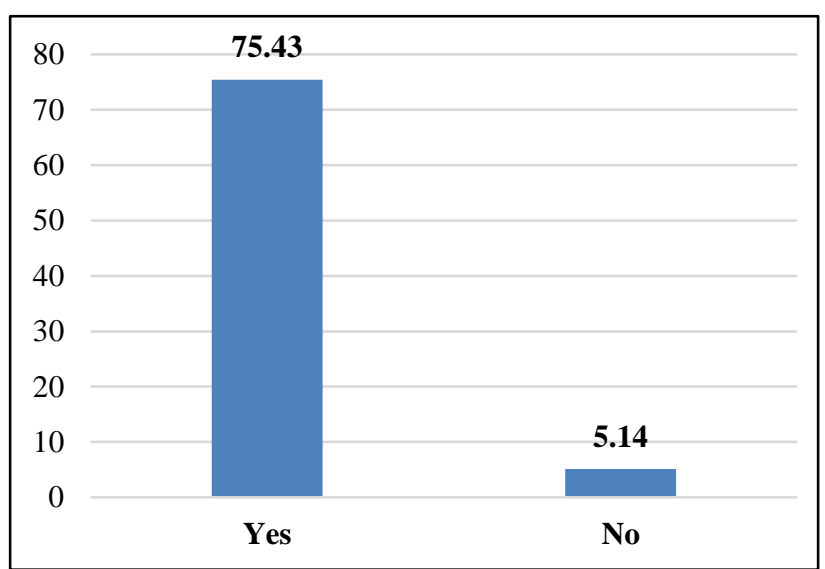

Figure 4: Percentage of drugs prescribed from hospital formulary.

\section{DISCUSSION}

India's pharmaceutical market is one of the largest markets in the world valued at more than US\$12 billion in 2009 and is expected to exceed $\$ 55$ billion in $2020 .^{9,10} \mathrm{~A}$ prescription by a doctor may be taken as an indication of the doctors' attitude towards the disease and the role of drugs in its treatment. The study evaluated the prescription pattern of FDCs in a tertiary care teaching hospital. The study showed the trend towards prescribing rational FDCs. The positive aspects of the study were not using the banned drugs in the hospital. There are also some limitations regarding small sample size, lack of indoor prescriptions and lack of enrollment of causality, TB chest, HIV and ICU patients. Approximately 53\% of FDCs were rational as they fulfilled all the WHO criteria. The most common examples were amoxicillin plus clavulanic acid, artemether plus lumifantrine, trimethoprim plus sulfamethoxazole, piperacillin plus tazobactam, Norethisterone plus ethinylestradiol. Some of the irrational combinations are paracetamol plus dicyclomine, alprazolam plus paracetamol, rabeprazole plus diclofenac, propantheline plus haloperidol. Eighty three percent of FDCs were prescribed by the brand names and only $17 \%$ of FDCs were prescribed by generic names. The cost effectiveness was indicated as $75.43 \%$ of the drugs were dispensed from hospital pharmacy.

Due to poorly enforced regulations and lack of laws for granting approval for new FDCs, India has a significant drug use problem. ${ }^{11}$ A 2012 report by the Parliament of India emphasized that new drug approvals were granted by the Central Drugs Standard Control Organization 
(CDSCO- the Indian regulatory body to ensure drug safety), in the absence of evidence of efficacy and without the necessary clinical trials. ${ }^{9}$ Such a pharmaceutical market is a fertile ground for irrational FDCs to flourish.

It is the need of time doctors should be made aware of the demerits of irrational prescribing and they should detain from prescribing irrational FDCs. Many studies have shown that education at an individual or small group level and peer education are effective strategies to change doctors' antibiotic prescribing behavior. ${ }^{12-14}$ To improve the overall drug use, especially in developing countries, international agencies like WHO and International Network for Rational Use of Drugs (INRUD) have applied themselves to evolve standard drug use indicators. ${ }^{15,16}$

\section{CONCLUSION}

Pharmaceutical manufacturers, however, continue to reap the benefits of huge sales, and therefore continue promoting them with vigor. Time has come for all of us, as practitioners and consumers, to raise this matter vociferously through all possible avenues. The campaign against meaningless FDCs must be carried on to every nook and corner of the country. The power vested in statelevel drug regulatory authorities is often taken advantage of by pharmaceutical companies who push through irrational combinations without proper scrutiny.

Therefore, in making this campaign a success we earnestly hope that our drug regulatory bodies would take urgent and stringent measures in mitigating such free flow of irrational FDCs.

While combining two drugs, the efficacy and bioavailability of the two drugs undergo a change on account of the reactions between these chemicals. Therefore, detailed clinical trials and bioavailability studies have to be completed before such products are allowed to be marketed. For serious ailments such as TB and AIDS patients intake of more than one drug at a time for longer treatment period is critical and drug combinations are justified for the sake of patient compliance. It is far above the ground that pharmaceutical companies, healthcare professionals and regulatory authorities join hands and prescribe guidelines and international standard for the manufacturing and sale of FDCs.

In a hospital, where hospital formulary is based on WHO Essential medicine list, hundred percent utilization of hospital pharmacy service doctors and patients would ensure rational prescribing benefits of the patients.

Funding: No funding sources Conflict of interest: None declared

Ethical approval: The study was approved by the Institutional Ethics Committee

\section{REFERENCES}

1. Patil PJ, Patil MJ, Patil VR, Deshmukh TA, Band SS: A survey on awareness of Fixed Dose Combinations (FDCs) among patients, physicians and pharmacists at Pune and Beed (India). Ind $\mathbf{J}$ of Phar Practic. 2013;6(3):49-52

2. Pradhan SC, Shewade DG, Shashindran CH, Bapna JS. Drug utilization studies. Natl Med J India. 1988;1:185-9.

3. Uppal R, Nayak P, Sharma PL. Prescribing trends in internal medicine. Int $\mathrm{J}$ Clin Pharm Ther Toxicol. 1984;22:373-6.

4. Srishyla MV, Krishnamurthy M, Naga Rani MA, Clare M, Andrade C, Venkataraman BV. Prescription audit in an Indian hospital setting using the DDD (defined daily dose) concept. Indian J Pharmacol. 1994;26:23-8.

5. WHO Technical Report Series, WHO expert committee on specifications for pharmaceutical preparations, $39^{\text {th }}$ report, Geneva, WHO. 2005.

6. McKinsey and Company. India Pharma 2020 Propelling access and acceptance, realising true potential. 2013. Available at: http://online.wsj.com/public/resources/documents/Mc KinseyPharma2020 ExecutiveSummary.pdf (accessed Jan 9, 2015).

7. Biswas NR, Biswas RS, Pal PS, Jain SK, Malhotra SP, Gupta AS, Pal SN. Patterns of prescriptions and drug use in two tertiary hospitals in Delhi. Indian J Physiol Pharmacol. 2000 Jan 5;44(1):109-12.

8. Shankar RP, Partha P, Nagesh S. Prescribing patterns in medical outpatients. Int J Clin Pract. 2002;56:54951.

9. Pollock EVA. The proliferation of irrational metformin fixed-dose combinations in India. The Lancet Diabetes and Endocrinology. 2015;3(2):98100.

10. Jain N, Akarte A, Deshmukh P, Kannojia P, Garud N, Yadav A. Rationality of Fixed Dose Combinations: An Indian Scenario. The Pharma Research. 2009;01:158-68.

11. Parliament of India: Rajya Sabha. Department-related Parliamentary Standing Committee on Health and Family Welfare. Fifty-ninth report on the functioning of the Central Drugs Standard Control Organisation (CDSCO). May 8, 2012. Available at: http://164.100.47.5/newcommittee/reports/englishco mmittees/committee\%20on\%20health\%20and\%20fa mily\%20 welfare/59.pdf (accessed Oct 9, 2014).

12. Belongia EA, Schwartz B. Strategies for promoting judicious use of antibiotics by doctors and patients. BMJ. 1998;317:668-71.

13. Schaffner W, Ray W, Federspiel C, Miller W. Improving antibiotic prescribing in office practice. JAMA. 1983;250:1728-32.

14. Ekedahl A, Anderson S, Hovelius B, Molstad S, Liodholm H, Melandor A. Drug prescription attitudes and behavior of general practitioners. Effects of 
problem oriented educational programme. Eur J Clin Pharmacol. 1995;47:381-7.

15. Nehru M, Kohli K, Kapoor B, Sadhotra P, Chopra V, Sharma R. Drug utilization study in outpatient ophthalmology department of government medical college Jammu. JK Science. 2005;7(3):149-51.

16. Maini R, Verma KK, Biswas NR, Agrawal SS. Drug utilization study in dermatology in a tertiary hospital in Delhi. Ind J Physiol Pharmacol. 2002 Jan 25;46(1):107-10.

Cite this article as: Tabish A, Khan TA, Chandel NB, Rao A, Mishra C. Rationality verses irrationality in fixed dose combinations: at a tertiary teaching hospital of rural Chhattisgarh, India. Int J Basic Clin Pharmacol 2018;7:1114-8. 